\title{
Management of Thoracolumbar Fractures
}

\author{
Sanjay Meena ${ }^{1}$ Pankaj Sharma ${ }^{2}$ Buddhadev Chowdhury ${ }^{2}$ \\ ${ }^{1}$ Department of Orthopaedics, SGT Medical College, Gurgaon, \\ Haryana, India \\ 2 Department of Orthopedics, All India Institute of Medical Sciences, \\ New Delhi, India \\ Indian J Neurosurg 2015;4:56-62. \begin{abstract}
New Delhi 110076, India (e-mail: sanjaymeena@hotmail.com).
\end{abstract} \\ Address for correspondence Sanjay Meena, MS, L-139, Sarita Vihar,
}
Abstract
Keywords
- thoracolumbar fracture
- spinal fractures
- pedicle screws
- spine fractures

Thoracolumbar region is the most commonly affected region of spine in trauma, but still no consensus exists on various aspects of its management. The management of thoracolumbar fractures has evolved considerably with time, but there are certain areas where there is still no consensus. Only few level I evidence are available to make any recommendation. This article reviews the current literature on evaluation, treatment, timing of surgery, choice of approach, and length of fusion.

\section{Introduction}

Thoracolumbar region is the most commonly affected region of spine in trauma, with fall from height being the most common cause. Dorsolumbar junction is more susceptible, as it is located between the stiff kyphotic dorsal spine and more mobile lordotic lumbar spine. ${ }^{1}$ More than $50 \%$ of thoracic and lumbar injuries occur between T11 and $\mathrm{L} 1 .^{2}$ Overall, 20 to $40 \%$ of these fractures are associated with neurological deficits. ${ }^{3}$ Contiguous and noncontiguous spine injuries are present in up to 17 to $20 \%$ of cases. ${ }^{4}$

Despite the frequency of these injuries, there remains considerable controversy regarding the most appropriate treatment. There are many factors that make assessing and treating patients with injuries to the spinal column and spinal cord demanding. ${ }^{5}$ The management of thoracolumbar fractures has evolved considerably with time, but there are certain areas where there is still no consensus. We reviewed the current diagnostic and therapeutic approach to this injury.

\section{Evaluation}

A thorough history should be obtained and the severity of trauma is noted, whether its high-energy or low-energy trauma. These patients are usually involved in high-energy trauma and have multiple associated injuries. ${ }^{6}$ Initial management should begin as per the protocol of advanced trauma life support. ${ }^{7}$ Treatment priorities include resuscitation and treatment of life-threatening injuries first, followed by mechanical restoration of injured osteoligamentous column and preservation or restoration of neurological function. At all-time cervical spine protection and log roll technique to transfer the patient should be used. A systematic approach would ensure that no injury is missed. The treating surgeon should take time to document the neurological status and associated injuries due to the medico legal significance of such cases. The neurological examination should consist of motor power testing, sensory testing, examination of reflexes, and bladder/bower involvement.

Spinal shock is a commonly used term but is poorly understood. It refers to a temporary dysfunction of spinal cord, with a loss of reflexes and sensorimotor function caudal to the level of injury. It is manifested by absence of anal wink and bulbocavernosus reflexes and by flaccid paralysis. The return of bulbocavernosus reflex heralds the resolution of spinal shock. An accurate evaluation of neurological status is possible once the bulbocavernosus reflex returns and the spinal shock ends. Differentiation between incomplete and complete spinal cord injury is possible only after this. Complete spinal cord injury is manifested by the total absence of sensory and motor function below the injury level. In an incomplete cord injury, received

June 28, 2014

accepted

May 25, 2015

published online

July 28, 2015
DOI http://dx.doi.org/

10.1055/s-0035-1558835. ISSN $2277-954 X$ (c) 2015 Neurological Surgeons' Society of India
License terms

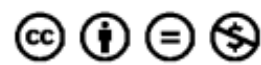


some residual function is preserved below the level of injury. Incomplete cord injury may manifest with any of the following four syndromes: Brown-Sequard syndrome, central cord syndrome, and anterior and posterior cord syndrome. ${ }^{8,9}$

Neurogenic shock refers to hemodynamic instability which accompanies spinal cord injury. It occurs because of the loss of sympathetic tone to peripheral vasculature and heart. It is manifested by the triad of bradycardia, hypothermia, and hypotension due to absent thermoregulation. This should be identified early as the management of neurogenic and hypotensive shock is very different. Hypotensive shock is managed with fluid and blood replacement while neurogenic shock is managed with vasopressors. Vigorous fluid administration in neurogenic shock may lead to pulmonary edema. $^{10}$

\section{Imaging}

Radiographs should include an anteroposterior (AP) and lateral view of the involved region. In lateral view following should be noted: vertebral body heights, alignment, angulation of spine, fracture of posterior wall cortex, and retropulsion of fragment into canal. In AP view, we look for alignment, interpedicular widening, and spinous process position. The plain radiographs have the limitation of not adequately visualizing thoracic spine, craniocervical junction, and cervicothoracic junction. The newer digital radiographs have overcome this limitation to some extent.

Computed tomographic scan is quick to perform and useful in polytrauma and unconscious/intoxicated patients. Detailed thin sliced $(1 \mathrm{~mm})$ axial CT scans with sagittal and coronal reconstructions scan further delineate the spinal fracture. ${ }^{11}$ Frequently, CT scan is performed for thoracic/abdominal trauma and spine evaluation can be performed without any increase in time or radiation. We routinely screen the whole spine to avoid missing any noncontiguous cord injury. Magnetic resonance imaging (MRI) is recommended for patients with neurological injuries to determine the extent of cord or cauda equina injury, epidural hematoma, and posterior longitudinal ligament complex integrity. ${ }^{12,13}$ The phase-locked loop integrity is a critical component of spinal stability and frequently guides the management of the fracture. ${ }^{14,15}$ There is an increase in severity of injury/change in classification once MRI is added to their protocol. ${ }^{16}$ However, Vaccaro et al in their prospective study to assess the accuracy of MRI in detecting posterior ligamentous complex (PLC) injury have concluded that PLC status could not be determined by MRI in isolation. ${ }^{17,18}$ The radiographic appearance of the fracture might not be accurate because of its closed reduction, which occurs when the patient is placed on a backboard. However, a careful clinical evaluation (history, mechanism of injury, local swelling, a palpable defect in interspinous ligaments, and a neurological deficit) and completed imaging studies (plain radiographs, CT scans, and MRI) can identify all the injuries. ${ }^{19}$ Edema extending more than two levels and presence of hematoma within the spinal cord are suggestive of poor prognosis.

\section{Fracture Classification}

To decide management, one needs to classify the fracture correctly. The classification system used should be reliable, reproducible, and certainly should help surgeon in deciding the management and evaluating outcome. Many classification systems have been described to guide the surgical treatment of thoracolumbar injuries. Traditionally, these injuries were classified by Denis three column concept. $^{20}$ These three columns are anterior, middle, and posterior, which are not detailed enough to account for all the fracture type. Of these three columns, the middle column provides the greatest mechanical stability. Other classification systems include Nicoll, Holdsworth, Magerl, $\mathrm{AO}$, and Load sharing classification. ${ }^{21-24}$ These classifications describe a static view of the injury and lack any treatment value. AO classification is too complex, lack reliability, and is difficult to apply in daily practice. Moreover, it does not take into consideration the neurological status of the patient ${ }^{25}$ (-Table 1). Currently, the classification system described by McAfee et al is the most widely used ${ }^{25}$ (- Fig. 1).

An ideal classification system should accurately describe the fracture, neurological status, stability, and determine the need for and potential type of surgery. The search for an ideal classification seems to end with the introduction of thoracolumbar injury severity score (TLISS) by spine trauma study group led by Vaccaro et al. ${ }^{15}$ This system quantifies the severity of injury and decides the management accordingly. This is one of the first classifications which included neurological function in its classification/score, the three main characteristics are as follows: (1) injury morphology, (2) neurological status, and (3) integrity of the PLC (-Table 2). Studies analyzing the interobserver reliability of this system have shown good reliability and reproducibility. ${ }^{26,27}$ We are regularly using TLICS in our practice and have found it really helpful. Whether one is using this system or not, but these three factors are always in one's mind while deciding the management of the patient.

\section{Operative versus Nonoperative Treatment Options}

Methylprednisolone was widely used initially after the recommendation of NASCIS II. $^{28}$ Multiple flaws in the study and conflict of interest in these studies were later detected, which makes its use controversial. However, most centers continue to use steroids in spine injury for fear of litigation. ${ }^{29,30}$

The aim of the treatment is restoration of maximum function of the patient, facilitating nursing care, and possibly neurological improvement or at least preventing further deterioration. The advantage of nonoperative method of treatment has been to avoid operative morbidity, such as, infection, iatrogenic neurological injury, pseudoarthrosis, implant failure, and complications of anesthesia. This option is reserved for patient with TLICS $<3$ and stable compression or burst fractures. Bracing has no role in traumatic thoracolumbar fractures, whether nonoperatively or operatively treated. 31,32 
Table 1 AO/MAEGRL classification

\begin{tabular}{|c|c|c|}
\hline Type & Group & Subgroup \\
\hline \multirow[t]{9}{*}{ A (compression) } & \multirow[t]{3}{*}{ A1: Impaction fractures } & A1.1 end plate impaction \\
\hline & & A1.2 wedge impaction \\
\hline & & A1.3 vertebral body collapse \\
\hline & \multirow[t]{3}{*}{ A2: Split fractures } & A2.1 sagittal split \\
\hline & & A2.2 coronal split \\
\hline & & A2.3 complete burst fracture \\
\hline & \multirow[t]{3}{*}{ A3: Burst fractures } & A3.1 incomplete burst fracture \\
\hline & & A3.2 burst-split fracture \\
\hline & & A3.3 complete burst fracture \\
\hline \multirow[t]{8}{*}{ B (distraction) } & \multirow[t]{2}{*}{ B1: posterior ligamentary lesion(subluxation) } & B1.1 with disc fracture \\
\hline & & B1.2 with type A fracture \\
\hline & \multirow[t]{3}{*}{ B2: posterior osseous lesion (spondylolysis) } & B2.1 transverse bicolumn \\
\hline & & B2.2 with disc rupture \\
\hline & & B2.3 with type A fracture \\
\hline & \multirow[t]{3}{*}{ B3: anterior disc rupture } & B3.1 hyperextension-subluxation \\
\hline & & B3.2 hyperextension-spondylolysis \\
\hline & & B3.3 posterior dislocation \\
\hline \multirow[t]{8}{*}{ C (rotation injury) } & \multirow{3}{*}{$\begin{array}{l}\text { C1: type A with rotation } \\
\text { (anterior-posterior dislocation) }\end{array}$} & C1.1 rotational wedge fracture \\
\hline & & C1.2 rotational split fracture \\
\hline & & C1.3 rotational burst fracture \\
\hline & \multirow[t]{3}{*}{ C2: type B with rotation (lateral shear) } & C2.1 B1 lesion with rotation \\
\hline & & C2.2 B2 with rotation \\
\hline & & C2.3 B3 with rotation \\
\hline & \multirow[t]{2}{*}{ C3: Rotational (rotational burst) } & C3.1 Slice fracture \\
\hline & & C3.2 Oblique fracture \\
\hline
\end{tabular}

Multiple studies have failed to show the functional benefit between operative and nonoperative treatment of stable injuries. $^{33,34}$ Operative management is related with better kyphosis correction but with similar pain and functional outcomes postoperatively. ${ }^{35}$ Conservative measures have shown to yield adequate results even in the presence of selective three column spine fractures and with early mobilization. $^{36}$ Spontaneous remodeling of the canal and resorption of retropulsed fragments have been observed in conservatively managed cases. ${ }^{37}$ It is imperative that nonoperative treatment should be closely monitored as there is the potential for progression of deformity. However, neurological worsening is rarely observed in a conservatively managed fracture. Patients with polytrauma are easily managed after spinal stabilization. Also, progressive neurological deficit indicates emergent decompression and stabilization. The mechanically unstable spine with translational displacement needs surgery. In severely injured patients' early intervention, results in fewer complications, shorter hospital stay, and reduced requirement for ventilation. ${ }^{38,39}$

Surgery is indicated, if the fracture is unstable or there is neurological deficit. Their criteria are as follows: loss of height $>50 \%$, Kyphotic deformity $>30$ degrees, PLC injury, progressive deformity, and progressive neurological deficit. Surgery is often decided by looking for the integrity of posterior ligamentous complex. One true indication for surgical intervention is the presence of progressive neurological deterioration in the presence of cord compression. When direct spinal canal decompression is promptly performed in such an injury, neurological recovery has been observed. ${ }^{40-42}$

\section{Surgeon}

Surgeon's expertise and available resources also have an important impact on types of intervention undertaken. In certain areas of the world where prolonged hospital care with bed rest is economically unviable, a surgical route will be undertaken to reduce costs for an injury that would easily be treated nonoperatively. If well-trained surgeons and hospital-based equipment is not available, then nonoperative treatment or referral to a properly equipped surgical center should occur. When deciding to manage the patient, the orthopedic surgeon is faced with the following 


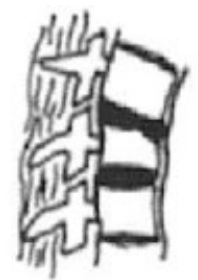

Compression Fracture

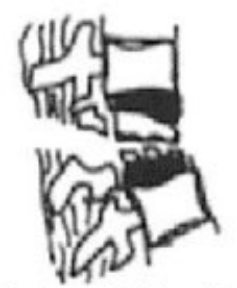

Flexion Distraction

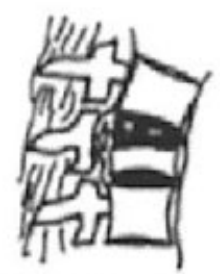

Burst Fracture

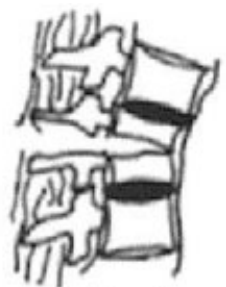

Chance Fracture

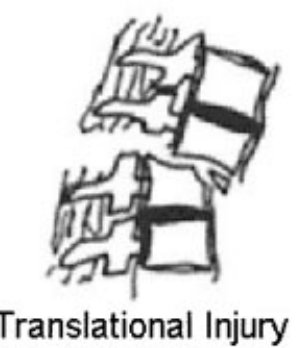

Fig. 1 McAfee classification.

three questions: whether to operate or not to operate, which approach to use, and how many levels to be fused.

\section{Timing of Surgery}

Early decompression has proven benefit in case of progressive neurological deterioration. In animals, rapid decompression appears to correlate with enhance recovery, but these benefits have not been shown in human studies. $^{43,44}$ It may be prudent to postpone definitive surgery till the patient is stabilized hemodynamically and associated injuries have been excluded.

There is considerable controversy with regards to the timing of surgery in the presence of neurological injury. Animal studies that showed early intervention had better results, which have failed to be proven in clinical setting in humans. Studies relating to timing of surgical intervention are few, and they relate to cervical cord injuries. We feel that the timing of surgery depends on hospital logistical and resource issues. It is not prudent to take the case in the middle of night. A skilled operative and anesthesia team ready to perform the surgery with adequate preoperative planning is more important than any patient-related variable, except occurrence of neurological deterioration. If the anterior approach is chosen, it is beneficial to wait 3-4 days after the injury which allows the period of hyperemia at the fracture site to resolve which decreases bleeding during the procedure. ${ }^{45}$

\section{Surgical Approaches}

Literature is still divided on the choice of approach. The choice of approach and need for decompression is corelated. If the patient has a neurological deficit and needs decompression then anterior approach would be suitable. ${ }^{45}$ Improved outcomes have been shown with the anterior approach. This has to do with the improved ability to decompress the canal with anterior approach. The odd of failure with posterior instrumentation is predicted by McCormack score. ${ }^{46}$ Posterior fixation is used for low-point total fractures (six or less) and anterior fixation only for highpoint injuries (seven or more). Injuries with translational displacement are treated with posterior fixation only in lowpoint injuries (less than seven) and a posterior followed by anterior approach for high-point injuries (seven or more). ${ }^{46,47}$ Load sharing between the implant and host bone is a fundamental principle that allows bone healing and prevents implant failure. If highly comminuted and displaced vertebral fractures are treated with posterior instrumentation only, pedicle screw breakage commonly occurs, as the load sharing across the fracture site itself is poor. When a single vertebral body is highly comminuted, anterior reconstruction of the spinal column and anterior instrumentation is superior to posterior fixation. Ligamentotaxis with posterior instrumentation is effective in reducing the retropulsed fragment only when done within a week or so. ${ }^{48-50}$ Combined anterior and posterior approach is used when canal is compromised circumferentially, severe coronal or sagittal plane deformity (> 40 degrees) or when structural augmentation is deemed necessary (osteoporosis, multiple contiguous levels of injury etc.). ${ }^{51}$

Although, no definitive literature exists supporting the benefits of decompression, but spine surgeon would decompress in a patient with neural compression having neurological deficit. ${ }^{52}$ Some animal studies do support decompression to restore regional blood flow. ${ }^{53}$ Direct decompression is not indicated if the patient has no neurological deficit even with significant canal encroachment at presentation, because this is not related to the development of a subsequent deficit. No studies have found a direct correlation between the percentage of canal compromise and severity of neurological deficit. ${ }^{54}$ An indirect decompression often is accomplished during operative stabilization for thoracolumbar injuries. Excellent spinal canal decompression can be achieved by either a posterolateral, transpedicular, or an anterior approach. The approach that affords the best opportunity for decompression is selected when a direct decompression is deemed warranted because fixation options have become more versatile, and stable fixation usually is possible with either anterior or posterior fixation and rarely combined fixation is necessary depending on which anatomical structures are injured. The options available to reconstruct the spinal column are full-thickness autologous iliac strut graft; cage spacer filled with autograft from the vertebrectomy and excised rib. Use of the modular cage avoids the large iliac crest donor site pain.

Regardless of the fixation system used, one must be careful not to over distract the fracture site. The normal sagittal and coronal spinal alignment must be restored with or without fully correcting the vertebral height. Overzealous distraction using a principle of ligamentotaxis creates a gap (empty space) at the fracture site which further decreases the load sharing of the axial forces between the implants and the fractured body, and also creates a risk of pseudoarthrosis and implant failure. Failure of the posterior systems occurs by breakage, bending, or loosening in patients. Whatever be the approach, these patients 
Table 2 Thoracolumbar injury severity score

\begin{tabular}{|c|c|}
\hline Parameters & Points \\
\hline \multicolumn{2}{|l|}{ Morphology } \\
\hline Compression & 1 \\
\hline Burst & 1 \\
\hline Translation/rotation & 3 \\
\hline Distraction & 4 \\
\hline \multicolumn{2}{|l|}{ Posterior ligamentous complex } \\
\hline Intact & 0 \\
\hline Suspected/indeterminate & 2 \\
\hline Injured & 3 \\
\hline \multicolumn{2}{|l|}{ Neurological status } \\
\hline Intact (ASIA-E) & 0 \\
\hline Nerve root & 2 \\
\hline \multicolumn{2}{|l|}{ Cord/conus } \\
\hline Complete (ASIA-A) & 2 \\
\hline Incomplete (ASIA-B, C, D) & 3 \\
\hline Cauda equine & 3 \\
\hline
\end{tabular}

Note: A score of $\leq 3$ indicates nonoperative treatment; $\geq 5$ indicates operative treatment.

should be given prophylaxis for deep vein thrombosis. This may include use of intermittent pneumatic compression devices, static compression stockings, and in pharmacologic prophylaxis (low-molecular-weight heparin)

\section{Length of Fusion}

Long segment fusion (instrumentation two or more levels above and below the fractured site) is stronger and stiffer than short segment fixation (instrumentation one level above and below the fractured vertebra); however, it sacrifices spinal motion. The location of the fracture can influence the surgeon's choice of fusion. A long fusion in the upper and middle thoracic spine does not reduce patient's spinal mobility and function very much. However, the thoracolumbar and lumbar spines are functionally very important. Preservation of mobility in these segments of the spinal column is fundamental-particularly in manual workers whose jobs require increase demands on the spine. Long construct may be more suitable in the setting of comminution and osteoporosis. Short-segment fixation may lead to higher rates of instrumentation failure and pseudoarthrosis when used for unstable injuries (e.g., extensive comminution, osteoporosis, and fractures of the thoracolumbar junction).

Pedicle screws provide three column bony fixation. One can safely use short segment pedicle screw-based fixation for low point total ( 6 points or less) spinal fractures without translation. When the pedicles are large enough to accept pedicle screws, we never use hooks and/or wires. While out of bed, the patient must wear a brace for 6 to 8 weeks until the fusion consolidates.
Anterior short segment instrumentation and fusion is used for patients with point totals of 7,8 , or 9 who have no translational displacement, for example, a fracture dislocation. Fracture dislocations are treated with posterior long-segment instrumentation and/or anterior procedures to reconstruct very severely comminuted vertebral bodies at the apex of these injuries.

\section{Minimally Invasive Treatment of Thoracolumbar Fracture}

Open surgery is associated with high morbidity, increased infection risk, and postoperative pain. To circumvent these problem, minimal invasive technique has been developed. ${ }^{55,56}$ The indications are as follows:

1. Posterior surgery following anterior decompression and reconstruction.

2. Percutaneous instrumentation in polytrauma.

3. Ankylosing spondylitis.

4. Alternative to bracing.

Minimally invasive instrumentation is technically demanding and may sometimes not be feasible, such as when patient requires direct decompression. The use of vertebroplasty or kyphoplasty with or without supplemental fixation is still under investigation.

Rehabilitation and community reintegration is a must. A good rehabilitation process may help many of these patients to return to their productive life earlier. If not managed properly, the late consequences of delayed neurologic deficit and painful kyphosis may significantly impair the quality of life of patient. ${ }^{57-59}$

\section{Conclusion}

Proper assessment and evaluation of these injuries are essential. Controversies still exist over indications of surgery, choice of approach, and length of fusion. In the absence of neurological insult, these injuries can be managed conservatively. In unstable injury with or without neurological deficit, surgical intervention is recommended. TLISS is helpful in guiding the management of the patients. Appropriate management and early rehabilitation helps to return many of such victims to productive lives earlier.

\section{Conflict of Interest}

The authors declare that they have no conflict of interest related to this article.

Financial Grant

None.

Acknowledgment

None. 


\section{References}

1 Gertzbein SD. Scoliosis Research Society. Multicenter spine fracture study. Spine 1992;17(5):528-540

2 DeWald RL. Burst fractures of the thoracic and lumbar spine. Clin Orthop Relat Res 1984;(189):150-161

3 Rajasekaran S, Kanna RM, Shetty AP. Management of thoracolumbar spine trauma: An overview. Indian J Orthop 2015;49(1):72-82

4 Tearse DS, Keene JS, Drummond DS. Management of noncontiguous vertebral fractures. Paraplegia 1987;25(2): 100-105

5 Gupta A, el Masri WS. Multilevel spinal injuries. Incidence, distribution and neurological patterns. J Bone Joint Surg Br 1989; 71(4):692-695

6 Cotler JM, Vernace JV, Michalski JA. The use of Harrington rods in thoracolumbar fractures. Orthop Clin North Am 1986;17(1): 87-103

7 Stein DM, Roddy V, Marx J, Smith WS, Weingart SD. Emergency neurological life support: traumatic spine injury. Neurocrit Care 2012;17(Suppl 1):S102-S111

8 Wirz M, Zörner B, Rupp R, Dietz V. Outcome after incomplete spinal cord injury: central cord versus Brown-Sequard syndrome. Spinal Cord 2010;48(5):407-414

9 Sidhu GS, Ghag A, Prokuski V, Vaccaro AR, Radcliff KE. Civilian gunshot injuries of the spinal cord: a systematic review of the current literature. Clin Orthop Relat Res 2013;471(12): 3945-3955

10 Vale FL, Burns J, Jackson AB, Hadley MN. Combined medical and surgical treatment after acute spinal cord injury: results of a prospective pilot study to assess the merits of aggressive medical resuscitation and blood pressure management. J Neurosurg 1997;87(2):239-246

11 Wintermark M, Mouhsine E, Theumann N, et al. Thoracolumbar spine fractures in patients who have sustained severe trauma: depiction with multi-detector row CT. Radiology 2003;227(3): 681-689

12 Lee HM, Kim HS, Kim DJ, Suk KS, Park JO, Kim NH. Reliability of magnetic resonance imaging in detecting posterior ligament complex injury in thoracolumbar spinal fractures. Spine 2000; 25(16):2079-2084

13 Lee JY, Vaccaro AR, Schweitzer KM Jr, et al. Assessment of injury to the thoracolumbar posterior ligamentous complex in the setting of normal-appearing plain radiography. Spine J 2007; 7(4):422-427

14 McEvoy RD, Bradford DS. The management of burst fractures of the thoracic and lumbar spine. Experience in 53 patients. Spine 1985;10(7):631-637

15 Vaccaro AR, Lehman RA Jr, Hurlbert RJ, et al. A new classification of thoracolumbar injuries: the importance of injury morphology, the integrity of the posterior ligamentous complex, and neurologic status. Spine 2005;30(20):2325-2333

16 Winklhofer S, Thekkumthala-Sommer M, Schmidt D, et al. Magnetic resonance imaging frequently changes classification of acute traumatic thoracolumbar spine injuries. Skeletal Radiol 2013;42(6):779-786

17 Vaccaro AR, Rihn JA, Saravanja D, et al. Injury of the posterior ligamentous complex of the thoracolumbar spine: a prospective evaluation of the diagnostic accuracy of magnetic resonance imaging. Spine 2009;34(23):E841-E847

18 Joaquim AF, Ghizoni E, Tedeschi H, Batista UC, Patel AA. Clinical results of patients with thoracolumbar spine trauma treated according to the Thoracolumbar Injury Classification and Severity Score. J Neurosurg Spine 2014;20(5):562-567

19 van Middendorp JJ, Patel AA, Schuetz M, Joaquim AF. The precision, accuracy and validity of detecting posterior ligamentous complex injuries of the thoracic and lumbar spine: a critical appraisal of the literature. Eur Spine J 2013;22(3): 461-474
20 Denis F. The three column spine and its significance in the classification of acute thoracolumbar spinal injuries. Spine 1983; 8(8):817-831

21 Nicoll EA. Fractures of the dorso-lumbar spine. J Bone Joint Surg Br 1949;31B(3):376-394

22 Holdsworth F. Fractures, dislocations, and fracture-dislocations of the spine. J Bone Joint Surg Am 1970;52(8):1534-1551

23 Louis R. Unstable fractures of the spine. III. Instability. A. Theories concerning instability [in French]. Rev Chir Orthop Repar Appar Mot 1977;63(5):423-425

24 Magerl F, Aebi M, Gertzbein SD, Harms J, Nazarian S. A comprehensive classification of thoracic and lumbar injuries. Eur Spine J 1994;3(4):184-201

25 McAfee PC, Yuan HA, Fredrickson BE, Lubicky JP. The value of computed tomography in thoracolumbar fractures. An analysis of one hundred consecutive cases and a new classification. J Bone Joint Surg Am 1983;65(4):461-473

26 Koh YD, Kim DJ, Koh YW. Reliability and Validity of Thoracolumbar Injury Classification and Severity Score (TLICS). Asian Spine J 2010;4(2):109-117

27 Lewkonia P, Paolucci EO, Thomas K. Reliability of the thoracolumbar injury classification and severity score and comparison with the denis classification for injury to the thoracic and lumbar spine. Spine (Philapa 1976) 2012;37(26): 2161-2167

28 Bracken MB, Shepard MJ, Collins WF, et al. A randomized, controlled trial of methylprednisolone or naloxone in the treatment of acute spinal-cord injury. Results of the Second National Acute Spinal Cord Injury Study. N Engl J Med 1990; 322(20):1405-1411

29 Eck JC, Nachtigall D, Humphreys SC, Hodges SD. Questionnaire survey of spine surgeons on the use of methylprednisolone for acute spinal cord injury. Spine (Phila Pa 1976) 2006;31(9): E250-E253

30 Hurlbert RJ, Moulton R. Why do you prescribe methylprednisolone for acute spinal cord injury? A Canadian perspective and a position statement. Can J Neurol Sci 2002;29(3):236-239

31 Giele BM, Wiertsema SH, Beelen A, et al. No evidence for the effectiveness of bracing in patients with thoracolumbar fractures. Acta Orthop 2009;80(2):226-232

32 Folman Y, Gepstein R. Late outcome of nonoperative management of thoracolumbar vertebral wedge fractures. J Orthop Trauma 2003;17(3):190-192

33 Shen WJ, Liu TJ, Shen YS. Nonoperative treatment versus posterior fixation for thoracolumbar junction burst fractures without neurologic deficit. Spine 2001;26(9):1038-1045

34 Seybold EA, Sweeney CA, Fredrickson BE, Warhold LG, Bernini PM. Functional outcome of low lumbar burst fractures. A multicenter review of operative and nonoperative treatment of L3-L5. Spine 1999;24(20):2154-2161

35 Celebi L, Muratli HH, Doğan O, Yağmurlu MF, Aktekin CN, Biçimoğlu A. The efficacy of non-operative treatment of burst fractures of the thoracolumbar vertebrae [in Turkish]. Acta Orthop Traumatol Turc 2004;38(1):16-22

36 Resch H, Rabl M, Klampfer H, Ritter E, Povacz P. Surgical vs. conservative treatment of fractures of the thoracolumbar transition [in German]. Unfallchirurg 2000;103(4): 281-288

37 Dai LY. Remodeling of the spinal canal after thoracolumbar burst fractures. Clin Orthop Relat Res 2001;(382):119-123

38 Chipman JG, Deuser WE, Beilman GJ. Early surgery for thoracolumbar spine injuries decreases complications. J Trauma 2004;56(1):52-57

39 Oner FC, Wood KB, Smith JS, Shaffrey CI. Therapeutic decision making in thoracolumbar spine trauma. Spine 2010;35 (21, Suppl):S235-S244

40 Dashti H, Lee HC, Karaikovic EE, Gaines RW Jr. Decision making in thoracolumbar fractures. Neurol India 2005;53(4):534-541 
41 Dai LY. Principles of management of thoracolumbar fractures. Orthop Surg 2012;4(2):67-70

42 Karaiković EE, Pacheco HO. Treatment options for thoracolumbar spine fractures. Bosn J Basic Med Sci 2005;5(2):20-26

43 Dimar JR II, Glassman SD, Raque GH, Zhang YP, Shields CB. The influence of spinal canal narrowing and timing of decompression on neurologic recovery after spinal cord contusion in a rat model. Spine (Phila Pa 1976) 1999;24(16):1623-1633

44 Chapman JR, Anderson PA. Thoracolumbar spine fractures with neurologic deficit. Orthop Clin North Am 1994;25(4):595-612

45 Esses SI, Botsford DJ, Kostuik JP. Evaluation of surgical treatment for burst fractures. Spine 1990;15(7):667-673

46 McCormack T, Karaikovic E, Gaines RW. The load sharing classification of spine fractures. Spine 1994;19(15):1741-1744

47 Parker JW, Lane JR, Karaikovic EE, Gaines RW. Successful shortsegment instrumentation and fusion for thoracolumbar spine fractures: a consecutive 41/2-year series. Spine 2000;25(9): 1157-1170

48 Crutcher JP Jr, Anderson PA, King HA, Montesano PX. Indirect spinal canal decompression in patients with thoracolumbar burst fractures treated by posterior distraction rods. J Spinal Disord 1991;4(1):39-48

49 Willén J, Lindahl S, Irstam L, Nordwall A. Unstable thoracolumbar fractures. A study by CT and conventional roentgenology of the reduction effect of Harrington instrumentation. Spine 1984;9(2): 214-219

50 Yazici M, Gulman B, Sen S, Tilki K. Sagittal contour restoration and canal clearance in burst fractures of the thoracolumbar junction (T12-L1): the efficacy of timing of the surgery. J Orthop Trauma 1995;9(6):491-498
51 Sasso RC, Cotler HB. Posterior instrumentation and fusion for unstable fractures and fracture-dislocations of the thoracic and lumbar spine. A comparative study of three fixation devices in 70 patients. Spine 1993;18(4):450-460

52 Boerger TO, Limb D, Dickson RA. Does 'canal clearance' affect neurological outcome after thoracolumbar burst fractures? J Bone Joint Surg Br 2000;82(5):629-635

53 Carlson GD, Minato Y, Okada A, et al. Early time-dependent decompression for spinal cord injury: vascular mechanisms of recovery. J Neurotrauma 1997;14(12):951-962

54 Yang M, Ding GZ, Xu ZJ. Surgical Outcome in Thoracolumbar Fractures Managed by Short-segment Pedicle Instrumentation. Ann Acad Med Singapore 2014;43(1):24-32

55 Charles YP, Zairi F, Vincent C, et al Minimally-invasive posterior surgery for thoracolumbar fractures: new trends to decrease muscle damage. Eur J Orthop Surg Traumatol 2012;22(1): $1-7$

56 Court C, Vincent C. Percutaneous fixation of thoracolumbar fractures: current concepts. Orthop Traumatol Surg Res 2012; 98(8):900-909

57 Oner FC, van der Rijt RR, Ramos LM, Dhert WJ, Verbout AJ. Changes in the disc space after fractures of the thoracolumbar spine. J Bone Joint Surg Br 1998;80(5):833-839

58 Wang XY, Dai LY, Xu HZ, Chi YL. Kyphosis recurrence after posterior short-segment fixation in thoracolumbar burst fractures. J Neurosurg Spine 2008;8(3):246-254

59 Dai LY, Jiang LS, Jiang SD. Conservative treatment of thoracolumbar burst fractures: a long-term follow-up results with special reference to the load sharing classification. Spine 2008;33(23):2536-2544 